\title{
Challenges to implementing bottom-up flood risk decision analysis frameworks: how strong are social networks of flooding professionals?
}

\author{
James O. Knighton ${ }^{1}$, Osamu Tsuda ${ }^{2}$, Rebecca Elliott ${ }^{3}$, and M. Todd Walter ${ }^{1}$ \\ ${ }^{1}$ Department of Biological and Environmental Engineering, Cornell University, Ithaca, 14850, USA \\ ${ }^{2}$ Department of Architecture, Art, and Planning, Cornell University, Ithaca, 14850, USA \\ ${ }^{3}$ Department of Sociology, London School of Economics, London, WC2A 2AE, UK
}

Correspondence: James O. Knighton (jok8@ cornell.edu)

Received: 11 June 2018 - Discussion started: 13 July 2018

Revised: 29 September 2018 - Accepted: 18 October 2018 - Published: 1 November 2018

\begin{abstract}
Recent developments in bottom-up vulnerabilitybased decision analysis frameworks present promising opportunities for flood practitioners to simplify complex decisions regarding risk mitigation and climate adaptation. This family of methodologies relies on strong social networks among flood practitioners and the public to support careful definition of stakeholder-relevant thresholds and vulnerabilities to hazards. In parallel, flood researchers are directly considering distinct atmospheric mechanisms that induce flooding to readily incorporate information on future climate projections. We perform a case study of flood professionals actively engaged in flood risk mitigation within Tompkins County, New York, USA, a community dealing with moderate flooding, to gage how much variance exists among professionals from the perspective of establishing a bottom-up flood mitigation study from an atmospheric perspective. Results of this case study indicate disagreement among flooding professionals as to which socioeconomic losses constitute a flood, disagreement on anticipated community needs, weak understanding of climate-weather-flood linkages, and some disagreement on community perceptions of climate adaptation. In aggregate, the knowledge base of the Tompkins County flood practitioners provides a well-defined picture of community vulnerability and perceptions. Our research supports the growing evidence that collaborative interdisciplinary flood mitigation work could reduce risk, and potentially better support the implementation of emerging bottomup decision analysis frameworks for flood mitigation and climate adaptation.
\end{abstract}

\section{Introduction}

Societal vulnerability to riverine flooding is a complex function of physical hydrological processes, overlaid with our economic relationship to the land (Wheater and Evans, 2009), community perceptions and responses to risk (e.g., Vinh Hung et al., 2007), and the fundamental ability of experts to clearly communicate these risks to facilitate decisions by policy makers (Pappenberger et al., 2013). Recent flood losses across North America, Europe, and Asia have been exacerbated by uninformed and inaccurate prior beliefs surrounding riverine flood hazards (Merz et al., 2015), fundamental issues in how governmental organizations store and leverage data (Lane et al., 2011; Harries and PenningRowsell, 2011), the cognitive biases of individuals (Merz et al., 2015; Harries, 2008), socially organized apathy (Norgaard, 2011), and governmental response to societal deviations from anticipated rational behavior (Lupton, 2013).

Riverine flood risk analysis is inherently difficult due to the infrequency of flooding events (Merz et al., 2015), a globally nonstationary climate leading to more extreme precipitation (Trenberth et al., 2011), often nonlinear hydrologic rainfall-runoff responses (e.g., Mathias et al., 2016), and complex human-flood interactions (e.g., Collenteur et al., 2015), all of which can act to limit the intuition of decision makers for understanding flooding risks and selecting mitigation options (Merz et al., 2015). For any given local flood risk, different data, models, and assumptions can be combined in various ways to yield alternative, reasonable measures of the "true" or "real" risk. 
Flooding governance is typically discussed as being "topdown" or "bottom-up." Top-down typically refers to a technocratic hierarchy, often in the form of national institutions acting as the sole decision makers (e.g., Serra-Llobet et al., 2016; Plate, 2002). These approaches have been associated with a reliance on hazard-based assessments of risk. Bottomup approaches, in contrast, leverage the knowledge, experiences, preferences, and vulnerabilities of end users explicitly in problem definition and selection of mitigation actions. In bottom-up approaches, decision-making is generally a collaborative process across institutions. Previous work has shown that flood risk mitigation can benefit from a combination of top-down and bottom-up approaches whereby decisions are collaboratively refined and implemented across institutions (Serra-Llobet et al., 2016), often with direct input from stakeholders (e.g., Edelenbos et al., 2017; J. Knighton et al., 2017). Pahl-Wostl et al. (2013) demonstrate, through a case study of three European nations, the relative benefits of different governance schemes. Top-down mitigation, as found in Germany, allowed for clearer roles in decisionmaking, centralized repositories of knowledge, and more rapid action within limited windows of opportunity. The vertically integrated approaches of the Netherlands and Hungary allowed for greater integration of new information into policy decisions. In an effort to tackle some of the "wicked problem" characteristics of water resources challenges, researchers have been engaged in developing bottom-up frameworks for decision-making with a focus on problems accompanied by deep uncertainty (e.g., Many-Objective Robust Decision Making Kasprzyk et al., 2013; Scenario Neutral Planning Prudhomme, 2010, Decision Scaling Brown et al., 2012) with applications developed specifically to aid flood risk decision analysis (e.g., Evers et al., 2018; J. Knighton et al., 2017).

Bottom-up decision analysis methodologies initially focus on understanding system vulnerabilities (i.e., what are the negative consequences of a flood that we wish to avoid?), mapping these vulnerabilities onto a wide range of plausible hazard scenarios (e.g., if an $n$-year flood occurs, which of the previously defined losses will we experience and possibly to what severity?), and then evaluating which of these hazard scenarios are most likely given our current understanding of atmospheric and hydrological processes. Flood decision-making can be stalled by contentious discussions about the reliability of hazard data (e.g., is climate change driving changes to local storms? Should climate change be accounted for in mitigation planning?). A bottom-up perspective can improve decision-making in that uncertain data and potentially controversial methodologies can be evaluated within the context of community risks. For example, climatechange-driven changes to storm intensity may not increase frequency severe economic losses, and therefore can possibly be disregarded. Such public debates over the "accuracy" of hazard data and risk estimation, of the kind illustrated by recurrent controversies surrounding flood insurance rate maps in the USA (Elliott and Rush, 2017), reflect a technocratic faith that pegs decision-making to the purported ability of risk analysis to arrive at single true estimates of risk, which models typically do not and cannot provide (Weinkle and Pielke Jr., 2017). Vulnerability-based assessments, by contrast, map hazards directly to community vulnerabilities in order to produce stakeholder-relevant predictions and outcomes, thereby enhancing the broader legitimacy of any subsequent actions taken.

This is not, however, how risk mitigation planning and design has historically been conceptually modeled within the USA. Instead, it has been treated as a top-down process, with knowledge transfer between two distinct groups comprised of lay people and experts (Wood et al., 2012; Birkholz et al., 2014), the former typically understood as being ignorant or "overly emotional" while the latter are presumed to be rational and "analytical" (Lupton, 2013). However, this fails to capture how both groups approach issues of risk and natural hazards. As discussed in Norgaard (2011), a "knowledge deficit" model that assumes lay people would take (rational) action if they "only knew" is too limiting, as it leaves aside the institutional structures (Harries and PenningRowsell, 2011) and cultural differences (e.g., Masuda and Garvin, 2006) that shape orientations to risk, institutional responses, and community vulnerabilities.

Furthermore, the simplistic distinction between professionals and lay people is often blurred in practice. Though the momentum driving flood risk mitigation originates at the federal level within the USA (Burby, 2001) and many other nations, implementation of national policies and redistribution of resources relies on social infrastructure at the local level (Few, 2003; Rauken et al., 2015; Vogel and Henstra, 2015). Within the USA, Canada, Australia, and Europe, flood governance is frequently the collective effort of organizations operating across scales, including governmental organizations, nongovernmental organizations (NGOs), privately owned firms, citizen-led groups, and private research organizations (Plummer et al., 2018). Within these organizations, the individuals who participate can be considered experts in one subdiscipline of flood risk mitigation, with shifting leadership roles throughout the process. For instance, governmental organizations may take the lead on policy and legislation, while privately owned firms contribute hydrologic modeling, and residents and citizen-led groups share knowledge about local vulnerabilities to and effects of exposure to flood risk. These coalitions benefit by leveraging the skills, knowledge, and social position of the varied organizations to more effectively reduce flooding risk.

Bottom-up decision analysis frameworks place emphasis on adequately understanding and conveying community vulnerabilities and historical risks into the decision space. These frameworks rely heavily on strong social networks among professionals and the public to bridge gaps among institutions while articulating stakeholder interests (Morss et al., 2005). Collaboration and stronger trust relationships among 
institutions and the public have previously led to more effective means of disaster risk mitigation and climate adaptation at the state level (Clarvis and Engle, 2015; Haer et al., 2016). Opportunities to limit cognitive biases should be explored to reduce institutional vulnerability to flooding (Merz et al., 2015), though few research projects have considered how differences among flooding practitioners may be understood or modified to further reduce vulnerability to flooding hazards (e.g., Morss et al., 2005; Downton et al., 2005).

Given the intensity and complexity of the cooperation and coordination required to plan and implement flood risk mitigation, establishing common understandings - of community vulnerability to flooding, baseline flood loss frequency, community willingness, and project-desired goals - is a challenging and nontrivial task (Pahl-Wostl, 2009), particularly given diverse backgrounds, education, work experience, and risk exposure of stakeholders found in interdisciplinary working groups. de Brito and Evers (2016) reviewed multi-criteria decision analysis efforts and found that interdisciplinary decision analysis efforts across multiple stakeholder groups (including both professionals and lay people) were rare. It is therefore worth re-examining existing social networks and constructs at the local level to determine where such common understandings can be enhanced in the context of bottom-up methodologies for flood risk analysis. This need is particularly relevant when flood risk mitigation planning incorporates climate adaptation goals surrounded by deep uncertainties (Downton et al., 2005; Merz et al., 2015).

We address this gap with a case study survey of 50 professionals working on riverine flood risk mitigation within Tompkins County, New York, USA. We define "professional" and "practitioner" here as a subset of flooding risk stakeholders within Tompkins County who have more agency around flood hazard mitigation than that of a community member stakeholder. Our operational definition of professional includes professionals in private practice and research, elected government officials, appointed government officials, governmental employees, and volunteer members of advocacy groups with a water resources focus. This focus allows us to understand how the social connectedness among flooding practitioners and their community influences the flood risk mitigation planning and design process. We specifically focus this research on understanding how well positioned this network of flooding professionals is to begin a bottom-up vulnerability-based flood hazard mitigation plan. The results of this research show that professionals are not a monolithic category, as they vary in their knowledge of historical hydrologic events, perceptions of existing flooding vulnerability and risk, and perceptions of the need to incorporate future climate estimates into flood risk mitigation planning and design at the outset of a flood mitigation planning process. We compare survey results to available hydrologic data to determine how classic approaches focused on hydrologic data can be supplemented with socio-hydrologic information, and identify opportunities for strengthening interdisciplinary networks.

\section{Methodology}

\subsection{Study region: Tompkins County}

Tompkins County lies within central New York, USA. Areas of high population density are clustered within 15 towns and villages, each developed adjacent to a fourth-order or higher stream. The county population is approximately 100000 people across $1300 \mathrm{~km}^{2}$, with a median household income of approximately USD 48000 (United States Census, 2017) (about USD 10000 below the 2016 median household income for the USA). Tompkins County legislature is presently composed of 10 registered Democrats, 4 registered Republicans, and 1 Independent (TC, 2018), suggesting a Democratic partisan lean.

Federal Emergency Management Adjacency (FEMA) flood insurance rate maps, last updated in 1996, suggest that 3749 parcels lie within the 100-year special flood hazard area, of which 1874 are located within the City of Ithaca. From 1978 through 2012, 229 flood loss claims (6.7 claims $\mathrm{yr}^{-1}$ ) were submitted through the National Flood Insurance Program (NFIP), totaling USD 1593201 $\left(\sim 46900\right.$ USD yr $\left.^{-1}\right)$ (TC, 2013). The Tompkins County Hazard Mitigation Plan, established in 2013 to review county flood losses and propose corrective actions, is updated annually.

Tompkins County contains four fourth-order or greater streams that are tributaries to Cayuga Lake. An active National Weather Service (NWS) flood stage has been established for USGS gage 04234000 (USGS, 2018), which is representative of flooding within the City of Ithaca, a low-lying densely populated community within Tompkins County. Based on annual peak flow records, exceedance of the $2 \mathrm{~m}$ levees or discharge in excess of $120 \mathrm{~m}^{3} \mathrm{~s}^{-1}$ within Fall Creek (adjacent to the City of Ithaca) is estimated to be a 9-year event (J. Knighton et al., 2017), though we note that this estimate may vary depending on the period of record considered.

Tompkins County receives an average of $1000 \mathrm{~mm}$ of precipitation annually, with $15 \%$ as snowfall (NCDC, 2018). The county is approximately $45 \%$ forested, $45 \%$ agricultural land use (row crops), and $10 \%$ urban (Fry et al., 2011). A shallow confining layer $(0.5$ to $1.5 \mathrm{~m})$ leads to a prevalence of saturation excess runoff (Easton et al., 2007). Regionally, surface runoff is primarily generated during the spring following extratropical rain-on-snow coincident with frozen or saturated soils and during the fall period of tropicalmoisture-derived precipitation (Knighton and Walter, 2016; J. Knighton et al., 2017; J. O. Knighton et al., 2017).

Recent trends in gaged streamflow across the Northeast USA suggest a more mild increase in extreme discharge rel- 
ative to the conterminous USA (Slater and Villarini 2016). Downscaled CMIP5 projections of future precipitation (projected years 2015-2100) suggest a slight increase in air temperatures and an associated increase in annual maxima precipitation intensity (Schoof and Robeson, 2016; Ning et al., 2015). Inter-seasonal predictions of future precipitation for Tompkins County show high variability, and potentially inaccurate estimates of seasonal extreme rainfall related to numerical and physical limitations of current general circulation models (GCMs) (Wobus et al., 2017; J. Knighton et al., 2017). The difficulty in predicting future extreme precipitation and strong influence of the land surface on flood runoff (Ivancic and Shaw, 2015; J. O. Knighton et al., 2017) has yielded projections of mild to no increase in future riverine flooding hazard in the Northeast USA, often accompanied by high uncertainty (e.g., Hirabayashi et al., 2013; Wing et al., 2018), or an average increase in risk, but with high spatial variability (e.g., Wobus et al., 2017). Broadly, this region exists with relatively high uncertainty with respect to future climate trends and riverine flood frequency. We anticipate that this lack of a clear signal from state-of-the-art climate and flood projections on the anticipated future flooding risk may create added difficulty and ambiguity for local decisions concerning the need for local climate adaptation.

\subsection{Questionnaire design}

Prior to designing the survey, we conducted semi-structured interviews (methodology described by Hermanowicz, 2002) with 10 flooding professionals within Tompkins County from January 2017 through August 2017. Each interview was initiated with a series of general questions on the topic of flooding, and shortly thereafter interviewees were encouraged to move the discussion in their own direction of interest. The purpose of these interviews was to develop an exhaustive inventory of themes concerning the challenges faced by professionals engaging in group decision-making and to catalogue ideas about flooding commonly held by flood risk mitigation practitioners. Common themes included a professional's understanding of where flooding has occurred frequently within the county, a professional's understanding of what socioeconomic losses constituted a flood, a professional's perceived community concern about shifting flooding risk under climate change, and potential disagreement among professionals around the design goals of a countywide flood mitigation project.

We distributed a questionnaire to community members who engage directly with flooding through development of policy and legislation, science and engineering, education, community outreach, and advocacy. Candidate participants were identified by the Tompkins County Environmental Management Council (EMC), the citizen advisory board to Tompkins County. The EMC's varied experience, longstanding community connections, and formal liaison role between the public, Tompkins County Planning Department, and Tompkins County Legislature allowed it to make informed selections for this study. A review of the final survey was performed by the Cornell University Institutional Review Board and found to have no ethical implications related to human subjects' participation. A draft of the survey is in the Supplement.

Survey questions were a mixture of Likert-scale questions, multiple choice selection, and open-ended response. The questionnaire was developed by the authors and piloted with five members of the Tompkins County EMC. The questionnaire was administered by email on 27 October 2017 via an online platform. Four survey responses were delivered on paper due to limited access to the internet.

The first goal of the questionnaire was to understand if historical socio-hydrologic data are distributed broadly among flood professionals within Tompkins County. The survey prompted recipients to enter anecdotal information on historical flooding events, specifically, location, date of event, magnitude (i.e., known high water elevations), and known economic losses. The survey then focused on collecting information on participants' perceptions of current regional flood hazard, risk, and community needs. Individuals were asked to determine what forms of social or economic loss constituted a flood. Individuals were then asked to report their perception of current flooding frequency within their community, and what frequency of flooding would be deemed acceptable. As recommended by Merz et al. (2014) flood studies may benefit from a consideration of how unique weather types and patterns impact flooding. In drawing this explicit link between global climate and local weather we may better understand potential nonstationary nature of flooding, and how and when climate adaptation should be considered within flood hazard mitigation. The final section of the survey aimed to determine an individual's understanding of how local and regional weather drive flooding within Tompkins County. We asked several questions aimed at understanding flood practitioners' perceptions of community knowledge and desires for climate adaptation planning.

As will be discussed in the results, our survey population was comprised of a relatively small working group of professionals within Tompkins County, New York $(n=50)$. Our focus on this specific population within Tompkins County led to an inherently small sample size, though the surveyed population was representative of a large proportion of the total population identified $(n=89)$. We therefore used qualitative interpretation of our survey results in place of formal statistical tests. Our survey question and all results are publicly available in Knighton (2018).

\subsection{Hydrometeorological data analysis}

Weather types and precipitation depth totals for historical events were determined using the daily historical precipitation record (NCDC, 2018), records of regional historical flooding (Johnson, 1936; Agel et al., 2015; NCDC, 2018), 
a catalog of tropical storms (Roth and Weather Predictions Center, 2012), and the personal account of Michael Thorne (City of Ithaca Superintendent of Public Works, personal communication, 2018) to identify two recent ice jam events. Return periods for extreme daily precipitation totals were estimated with NOAA Atlas 14 (Percia et al., 2015).

We compare the spatial distribution of flooding as estimated from the FEMA National Flood Hazard Layer (NFHL) 100-year floodplain (FEMA, 2018) and flood practitioner reports.

Historical streamflow records were collected for Fall Creek (USGS, 2018) for the period of 1925 to 2018. We use an annual block maxima approach to identify the significant floods within the publically available long-term hydrologic record. We compare reports of historical flooding from community members to understand how we can best develop a complete record of county flooding.

\section{Results}

\subsection{Response rate}

The survey was distributed to 89 professionals, of which 50 responded (response rate of $56 \%$ ). Individuals were asked to self-sort into one of six possible roles: community planning $(n=8)$, education and outreach $(n=8)$, local government leadership $(n=9)$, policy $(n=5)$, advocacy $(n=9)$, and Engineering, Science and Research (ESR; $n=11$ ). We first asked flooding professionals whether they believed they had a good understanding of flood risk mitigation, to which $52 \%$ indicated they had a strong grasp of the subject, $38 \%$ knew of a professional who could inform them, and $10 \%$ were not knowledgeable on the subject (two policy, one education and outreach, one government, and one advocacy).

\subsection{Spatial distribution of socioeconomic flood losses}

Anecdotal reports of flooding were compiled to provide a spatial depiction of commonly flooded locations within Tompkins County (Fig. 1), as recalled by research participants. Anecdotal flood reports by community members demonstrate that flooding is a countywide issue, with the most commonly recollected flooding centered on the most densely populated areas. The reported locations of flooding cover substantially more locations than those falling within the official 100-year special flood hazard area, as depicted on FEMA's flood insurance rate map (FEMA, 2018). This is typical of many flood-prone areas; over $20 \%$ of flood insurance claims come from losses outside of currently mapped high-risk zones (where flood insurance is available but not mandatory) (FEMA, 2015).

NWS flood stage on Fall Creek in Ithaca is estimated to be exceeded with a 9-year recurrence interval. However, reported dates of flooding events (Table 1) suggest that for much of Tompkins County, professionals have collected in-

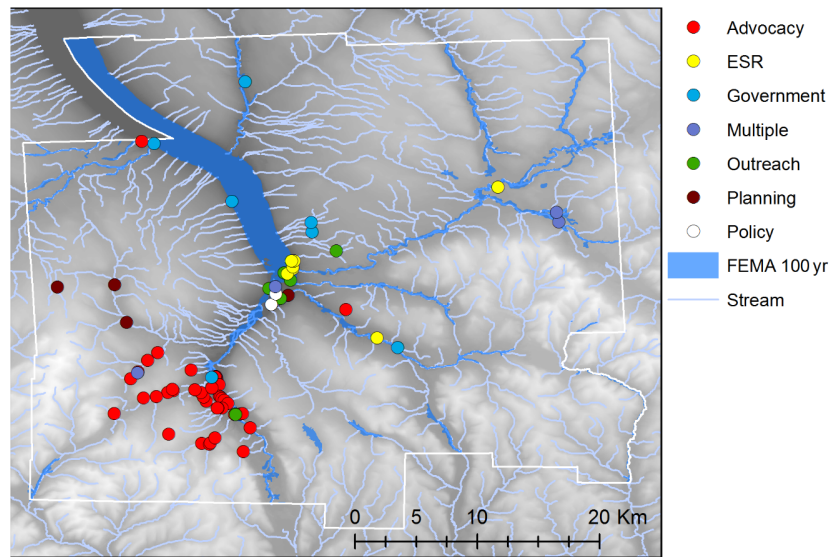

Figure 1. Spatial distribution of survey-reported flooding within Tompkins County (filled circles) and FEMA 100-year flood plain (dark blue).

formation on negative socioeconomic consequences from events that are hydrologically more frequent than the 9-year Fall Creek baseline, suggesting that primary sources of hydrologic data alone do not provide a complete depiction of flooding hazards within the county.

Weather types assigned to each reported historical flooding event indicate that flooding has been induced by local extreme convective precipitation, tropical-moisture-derived precipitation, extratropical rain-on-snow/snowmelt, and ice jams. Weather types for events prior to 1930 were not identified due to inconsistency among available sources.

\subsection{Defining flooding by socioeconomic losses}

Exploratory interviews with community leaders suggested that there were 13 socioeconomic losses that individuals commonly used to define a past flooding event (Table 2). The survey presented these 13 possible flooding losses and asked flooding practitioners to define which types of loss constituted a flood. Surveyed individuals also had the option to write in their own preferred definition.

No single type of reported flood was held common to all individuals surveyed (Table 2). The belief that negative flood consequences related to minor erosion in the stream channel and flow above baseflow constituted a flood was only held by a few respondents. Individuals in planning, government, and advocacy were more likely to hold a broad definition of flooding, whereas individuals in outreach, policy, and ESR tended to hold a narrower definition of flooding (Fig. 2). About $40 \%$ of ESR responses opted to use a write-in definition based on numeric description of flood frequency, for example, "any flow exceeding a storm recurrence interval 100 years or greater". 
Table 1. Reported historical flooding events. Rainfall totals are the maximum daily precipitation (NCDC, 2018). Return periods are determined from NOAA Atlas 14 (Percia et al., 2015).

\begin{tabular}{lrrl}
\hline $\begin{array}{l}\text { Date } \\
(\mathrm{m} / \mathrm{d} / \mathrm{yr})\end{array}$ & $\begin{array}{r}\text { Rainfall } \\
\left(\mathrm{cm} \mathrm{day}^{-1}\right)\end{array}$ & $\begin{array}{r}\text { Return period } \\
(\mathrm{yr})\end{array}$ & Weather type \\
\hline $4 / 18 / 1905$ & 1.2 & $<1$ & - \\
$6 / 3 / 1905$ & 4.3 & $<1$ & - \\
$6 / 17 / 1905$ & 4.6 & $<1$ & - \\
$7 / 3 / 1905$ & 4.8 & $<1$ & - \\
$7 / 8 / 1935$ & 20.0 & $<1$ & Hurricane Hazel \\
$11 / 3 / 1954$ & 4.0 & 10 & Hurricane Agnes \\
$6 / 23 / 1972$ & 9.0 & 25 & Local convective rain \\
$10 / 28 / 1981$ & 12.9 & $<1$ & Rain on snow \\
$1 / 19 / 1996$ & 4.7 & 2 & Rain on snow \\
$4 / 3 / 2005$ & 5.7 & 25 & Tropical Storm Lee \\
$9 / 8 / 2011$ & 11.3 & $<1$ & Ice jam \\
$1 / 11 / 2014$ & 0.0 & 10 & Local convective rain \\
$6 / 14 / 2015$ & 10.4 & $<1$ & Local convective rain \\
$7 / 1 / 2017$ & 0.9 & $<1$ & Ice jam \\
$1 / 12 / 2018$ & 2.4 & Tropical/local convective rain \\
\hline
\end{tabular}

* Statewide flooding was reported to result from a mixture of a tropical moisture export and local convective rainfall.

Table 2. Results of which socioeconomic losses were considered a flooding event. Types 14 and 15 are write-in responses.

\begin{tabular}{llr}
\hline Type & Description of flood & $\begin{array}{r}\text { Number of } \\
\text { Responses }\end{array}$ \\
\hline 1 & Loss of life & 29 \\
2 & Damage to private structures & 32 \\
3 & Displacement of people & 34 \\
4 & Damage to vehicles & 30 \\
5 & Damage to public property & 34 \\
6 & Inundation of public roads & 34 \\
7 & Flow over private property & 21 \\
8 & Backed up culverts & 25 \\
9 & Loss of streamside vegetation & 29 \\
10 & Stream flow out of channel banks & 32 \\
11 & Substantial erosion in the stream channel & 24 \\
12 & Minor erosion in the stream channel & 4 \\
13 & Any flow greater than baseflow & 11 \\
14 & Discharges above an $n$-year recurrence interval & 4 \\
15 & Any negative impact to resources & 1 \\
\hline
\end{tabular}

\subsection{Perceptions of current and desired flood frequency}

Estimates of the current flooding return period for Tompkins County varied slightly by discipline; however, most estimates were below the baseline flood return period established for Fall Creek of the 9-year event (Fig. 3a). The desired reduction in flooding return period varied considerably by discipline. The median ESR, community planning, and outreach response suggests that the expected flood frequency after mitigation efforts should be slightly higher than current flooding hazard (Fig. 3b). The median responses from governmental employees working on legislation and policy desired flood frequency to be reduced to the 100-year event,
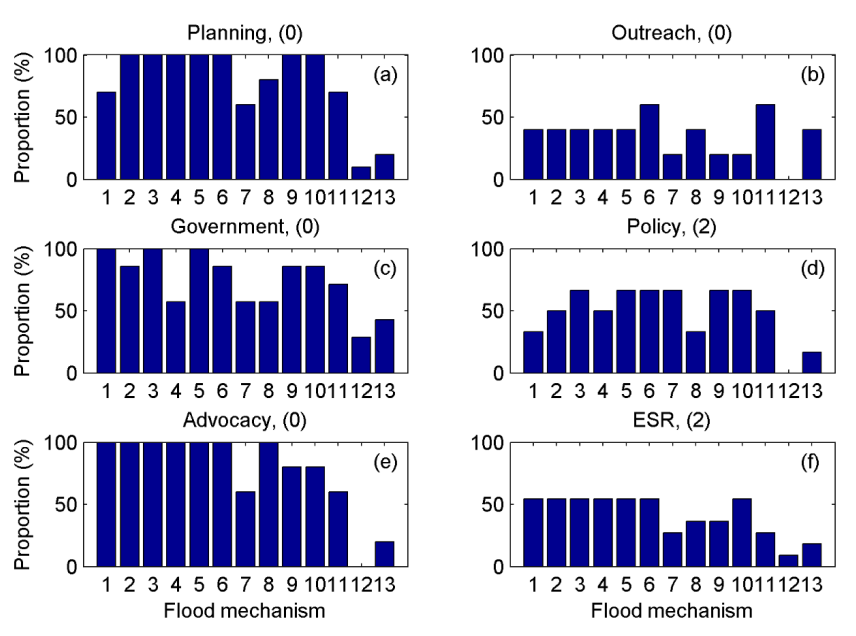

Figure 2. Socioeconomic losses that defined flooding events by discipline (Table 2 subset by discipline). Values in parentheses indicate the number of respondents who did not offer an answer.

suggesting a high level of disagreement between disciplines on anticipated outcomes of flood hazard mitigation. This difference could potentially be due to governmental focus on well-established floodplain thresholds (FEMA, 2018) versus perceptions of the physical limits of hydrologic alteration.

There was strong consistency in the perception of current flooding risks (Fig. 3a), though the spatial distribution of affected locations was highly individual (Fig. 1). This result suggests that individuals within Tompkins County have a consistent understanding of the frequency of these socioeconomic losses; however, there may not be a strong social net- 

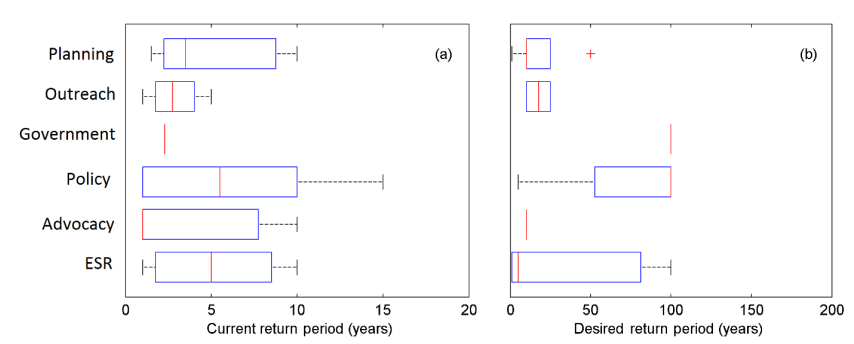

Figure 3. Estimated (a) current flood loss return period and (b) desired return period resulting from flood hazard mitigation efforts. Reports of desired frequency above 100 years are presented as 100year for visualization. Red lines indicate the median.

work for communication of risks as knowledge was spatially constrained by discipline. The Tompkins County hazard mitigation plan contains county records of historical events. This record is presently derived exclusively from federal sources (TC, 2013; NCDC, 2018), with no formal mechanism to collect and archive anecdotal accounts of flooding within the community. In the absence of a centralized county database to collect and share personal experiences among professionals, an individual's primary spatial knowledge of flooding may be most derived from their own individual experiences, related to place of residence or locations of previous work. Local flood hazard mitigation plans in the USA typically suffer from low quality as they are primarily developed as a requirement to maintain access to federal funding instead of functional plans for risk mitigation (Lyles et al., 2014).

We compare aggregated reports of flooding (Fig. 1, Table 1) to the long-term historical record of Fall Creek (Fig. 4a and b). Results indicate that aggregated records from all community members successfully identify the substantial flooding events for which Fall Creek overtopped the $2 \mathrm{~m}$ levee or greatly exceeded the channel capacity of $120 \mathrm{~m}^{3} \mathrm{~s}^{-1}$. It is worth noting that prior to 1970 annual peak flow frequently exceeded $120 \mathrm{~m}^{3} \mathrm{~s}^{-1}$, yet did not exceed the current NWS flood stage of $2 \mathrm{~m}$. This could be due to a change stream discharge monitoring, or a physical change in the stream rating curve. It was beyond the scope of this study to investigate the cause of the shift in hydrologic response.

The continuous hydrologic data of Fall Creek discharge and stage do not successfully identify all reported flooding events. Though Fall Creek is the largest watershed within Tompkins County (contributing drainage area of $325 \mathrm{~km}^{2}$ ) and has been monitored continuously for over a century, a purely hydrologic-hazard-based assessment considering only primary hydrologic measurements does not provide a complete picture of flooding across the county. The large contributing drainage area (time of concentration $\sim 6 \mathrm{~h}$ ) results in a hydrologic system sensitive only to weather events on the order of $6 \mathrm{~h}$ or longer. Continuous hydrologic monitoring records contain accurate information at the location of measurement, which is useful for developing flood frequency
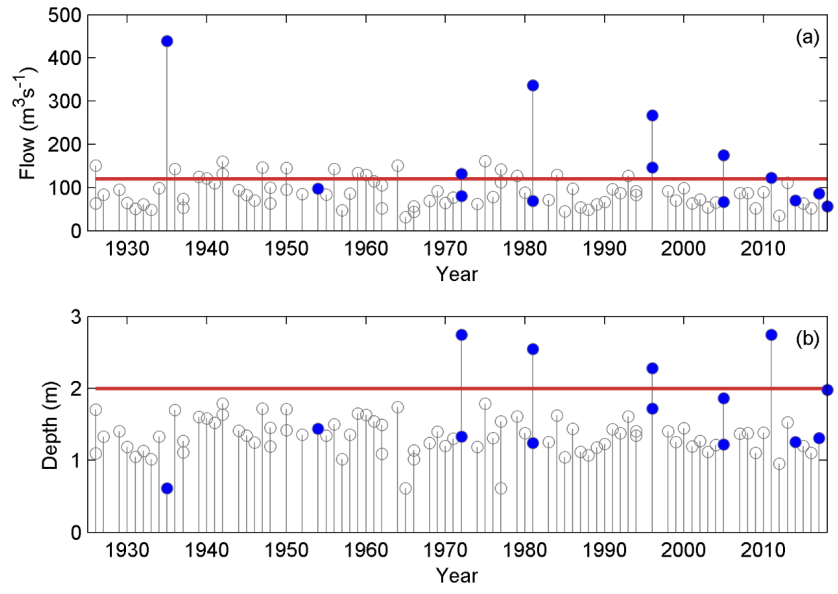

Figure 4. Annual block maxima: (a) peak instantaneous discharge and (b) peak stage for Fall Creek. Blue dots indicate that the event was identified as a flood by at least one survey response. Red lines indicate the hazard thresholds for (a) exceeding channel capacity, and (b) overtopping the $2 \mathrm{~m}$ levee within the City of Ithaca.

curves and hydrologic models. Survey reports of flooding, while less quantitative, benefit from broader spatial coverage and often include anecdotal accounts of socioeconomic losses (e.g., Marjerison et al., 2016). Together, primary hydrologic measurements (e.g., continuous stream depth) and anecdotal survey reports of flooding losses help to develop a more complete picture of the flooding hazard and risk profile within Tompkins County.

\subsection{Climate-flood linkages}

Surveyed individuals were asked to report which type of weather mechanism ( 1 - extratropical system, 2 - local convective rainfall, 3 - tropical moisture derived rainfall, 4 snowmelt events, 5 - ice jam) contributed to flooding within Tompkins County, with the option to write in flooding mechanisms. Optional write-in mechanisms included "Sever [sic] thunderstorms," "dramatic increase in stream levels for any reason", and "extreme rain". Responses and write-in results suggest that there is a general understanding that rainfall and air temperatures relate to flooding events; however, there was no strong agreement within any group that a given weather mechanism contributed directly to flooding outside of county planners agreeing that local convective rainfall contributed to flooding (Fig. 5). This result suggests that practitioners may have a limited understanding of weather-flood linkages.

It is worth noting that on 11 January 2018, while the online survey was active, a joint snowmelt-ice jam event caused nuisance flooding throughout the City of Ithaca (Ithaca Times, 2018). We anticipated this specific event would result in a strong agreement among professionals on the relationship between ice jams, snowmelt, and flooding due to recency bias. However, this was not reflected in the survey 

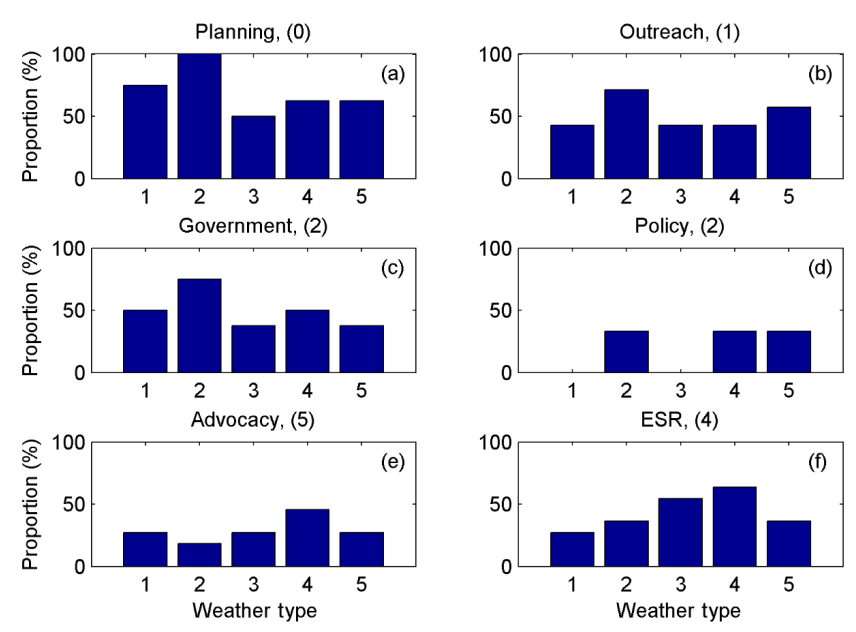

Figure 5. Reported flooding mechanisms that contribute to local flooding: 1 - extratropical system, 2 - local convective rainfall, 3 tropical moisture derived rainfall, 4 - snowmelt events, 5 - release of ice jam. Values in parentheses indicate the number of respondents who did not offer an answer.

Table 3. Perceptions of future riverine flooding risk within Tompkins County by flooding practitioners.

\begin{tabular}{lrrrr}
\hline & $\begin{array}{r}\text { Not } \\
\text { sure }\end{array}$ & $\begin{array}{r}\text { Less } \\
\text { risk }\end{array}$ & $\begin{array}{r}\text { Same } \\
\text { risk }\end{array}$ & $\begin{array}{r}\text { More } \\
\text { risk }\end{array}$ \\
\hline Community planning & 0 & 0 & 0 & 8 \\
Education and outreach & 1 & 0 & 1 & 5 \\
Local government leadership & 2 & 0 & 1 & 5 \\
Policy development & 3 & 0 & 0 & 2 \\
Public advocacy & 3 & 0 & 0 & 6 \\
ESR & 4 & 0 & 3 & 4 \\
\hline Total & 15 & 0 & 5 & 30 \\
\hline
\end{tabular}

results, with only $48 \%(n=24)$ and $38 \%(n=19)$ of all responses suggesting snowmelt and ice jam release, respectively, were important flooding mechanisms within Tompkins County.

Anticipation of the need to incorporate climate adaptation into flood risk planning, as well as anxiety around "community perceptions" and "public opposition to planning for climate change" were common themes that emerged during the 2017 semi-structured interviews. Flooding practitioners were asked which direction they anticipated future flooding risk within Tompkins County would move. The majority of individuals, 30, believed that flooding risk would increase, and 15 responded that they were not sure (Table 3).

Surveyed professionals were asked if they perceived a community desire to implement climate adaptation practices in flood mitigation planning. The result here was less clear, with 18 responding they were not sure, 7 probably not, 15 probably yes, and 6 definitely yes (Table 4). The Tompkins County Planning Department acknowledges hazards posed by climate change and the need for climate adaptation; however, the current county plan only focuses on maintaining existing natural and built infrastructure. No large-scale flood mitigation projects currently incorporate climate adaptation in planning and design (TC, 2015). There was some disagreement among disciplines on public preference for climate adaptation, with ESR and public advocacy perceiving less interest, and outreach and government perceiving more interest (Table 4).

We next asked practitioners to report their perceptions of the level of climate science knowledge of residents of Tompkins County. Results were divided, with 16 responding that they were not sure, 16 believing that residents had basic knowledge, and 10 believe strong knowledge. Results were not substantially different among the disciplines (Table 5).

\subsection{Optional write-in responses}

At the conclusion of the survey professionals were given the option to provide any additional information or thoughts on the topic beyond the survey responses provided. We summarize here the results of these submissions. Though we do not aim to interpret these results, they can offer important insights beyond what was captured in the survey questions.

Five professionals supplied optional comments in which they said that they had little knowledge of community perceptions and expressed difficulty in answering these particular questions, with one professional suggesting that community perception was perhaps too broad to accurately define with one single answer. Three responses suggested that they had a good understanding of community perceptions through involvement with county government and expressed that there was a willingness among the Tompkins County public to involve climate adaptation practices in flood risk mitigation. Four responses attributed recent flooding events to improper control of existing flood mitigation infrastructure by local, state, and federal government. One response listed the ecological benefits of flooding, and suggested that rather than seek mitigation opportunities to control floods, we seek to adapt human behavior.

\section{Discussion}

\subsection{Definitions and extents of flooding}

"How do we define a flood event?" and "What are the community vulnerabilities?" appear to be critical questions for which establishing consensus may prove difficult. Formal definitions of flooding used within the ESR community, which focus on quantitative flood frequency, are more hazard-oriented, whereas the definitions preferred by planning, government, advocacy, and outreach utilized the socioeconomic losses to define flooding. A focus on hazard may simplify engineering design and planning; however, it can potentially be too limiting to properly address other 
Table 4. Perceptions of community desire to implement climate adaptation planning in flood risk mitigation.

\begin{tabular}{lrrrrr}
\hline & $\begin{array}{r}\text { Note } \\
\text { sure }\end{array}$ & $\begin{array}{r}\text { Definitely } \\
\text { not }\end{array}$ & $\begin{array}{r}\text { Probably } \\
\text { not }\end{array}$ & $\begin{array}{r}\text { Probably } \\
\text { yes }\end{array}$ & $\begin{array}{r}\text { Definitely } \\
\text { yes }\end{array}$ \\
\hline Community planning & 2 & 0 & 1 & 5 & 2 \\
Education and outreach & 1 & 0 & 0 & 4 & 0 \\
Local government leadership & 1 & 0 & 1 & 4 & 1 \\
Policy development & 5 & 0 & 0 & 0 & 1 \\
Public advocacy & 2 & 0 & 2 & 1 & 0 \\
ESR & 5 & 0 & 3 & 1 & 2 \\
\hline Total & 18 & 0 & 7 & 15 & 6 \\
\hline
\end{tabular}

stakeholder needs. A conceptual disconnect on the definition of flooding points to issues with the core problem statement that coalitions of flooding professionals are self-organized to solve.

While formal guidelines exist at the US national level (Obama, 2015), these definitions often conflate risk and hazard. Formal federal definitions in the USA commonly focus on hydrologic hazard posed by a static water surface elevation, as in FEMA flood insurance rate maps (FEMA, 2018), neglecting hazard associated with discharge velocity, duration of inundation, and suspended material. In addition, the focus on hydrologic hazard can obscure from view the uneven socio-spatial distribution of exposure and vulnerability, which often aligns with prevailing axes of inequality along lines of race and class. The same flood event may be a nuisance for an affluent community and complete devastation for a poor one. Differences in reported flooding locations between the survey and established FEMA flood zone maps (Fig. 1) could potentially be explained by the distinction between hazard- and vulnerability-based definitions of flooding. For instance, when floods hit particularly vulnerable communities, their impacts may be dramatized in ways that allow them to retain salience in the minds and memories of stakeholders.

Gober and Wheater (2015) propose a broad reconceptualization of flood risk analysis that accounts for emergent and complex interactions between water and society including the role of social memory in magnifying risk perception (Di Baldassarre et al., 2015) or actual risks (Collenteur et al., 2015), public perception, policy limitations, windows of opportunity, and an imperfect flow of knowledge through society. Such conceptual models may extend unrealistically beyond the capacity of local flood professionals, though we can consider that expanding the definition of flooding beyond the traditional flood frequency realm could allow practitioners to more easily realize the benefits of bottom-up flood risk analysis frameworks. Flooding practitioners increasingly face decisions about the appropriate level of abstraction when defining socio-hydrology problem statements (Troy et al., 2015; Blair and Buytaert, 2016). Preemptively limiting the complexity of a problem in the planning stage possibly intro- duces new vulnerabilities in the form of "surprise" (Merz et al., 2015). It is possible that surprise can be avoided or reduced, even without consensus on community vulnerability through encouraging interdisciplinary discourse (Di Baldassarre et al., 2016).

\subsection{Perceptions of climate-weather-flood linkages and climate adaptation planning}

Researchers are moving towards reframing flooding risk from the perspective of the distinct atmospheric mechanisms that induce floods (Merz et al., 2014) in an effort to simplify the interpretation of how mesoscale global trends (e.g., global climate change, decadal global oscillations) influence local weather patterns and subsequently local flooding. Within the Northeast USA, this problem is often expressed as nonstationary rainfall intensity and warming air temperatures that may drive flooding hazards (e.g., DeGaetano, 2009).

Current climate projections of summer extreme precipitation for Tompkins County predict increases in air temperatures and precipitation intensity (DeGaetano, 2009), though regional estimates of future flooding hazard are accompanied by high uncertainty (J. Knighton et al., 2017). While warming air temperatures are likely to enhance the melt rate of the standing snowpack, it could also limit total snowpack accumulation, tempering the effect of climate change on winter flooding (J. O. Knighton et al., 2017). Similarly, during the summer season warming air temperatures will likely result in reduced soil moisture, tempering extreme runoff. Though an increase in the intensity of precipitation is often expected to translate directly into increased discharge (e.g., Trenberth, 2011), this outcome is not necessarily expected in the Northeast USA (Ivancic and Shaw, 2015).

Emerging methods of flood analysis attempt to limit the need for coarse interpretations of changes to extreme rainfall as projected by highly uncertain GCMs, by drawing explicit connections from climate change to weather types and then local flood risk (e.g., J. Knighton et al., 2017). While these approaches can potentially better allow local professionals to address climate adaptation within this high uncertainty decision space, they rely on a baseline of knowledge 
Table 5. Perceptions of general community knowledge level of climate science and adaptation.

\begin{tabular}{lrrrr}
\hline & $\begin{array}{r}\text { Not } \\
\text { sure }\end{array}$ & $\begin{array}{r}\text { Little } \\
\text { knowledge }\end{array}$ & $\begin{array}{r}\text { Basic } \\
\text { knowledge }\end{array}$ & $\begin{array}{r}\text { Strong } \\
\text { understanding }\end{array}$ \\
\hline Community planning & 1 & 0 & 3 & 5 \\
Education and outreach & 1 & 0 & 3 & 1 \\
Local government leadership & 1 & 2 & 2 & 2 \\
Policy development & 5 & 0 & 1 & 0 \\
Public advocacy & 1 & 1 & 2 & 1 \\
ESR & 5 & 0 & 5 & 10 \\
\hline Total & 16 & 3 & 16 & \\
\hline
\end{tabular}

around established climate-flood linkages. As demonstrated in Table 1, individuals reported historically significant flooding events. Through a simplistic weather-typing analysis, we determined that these events encompassed the atmospheric mechanisms of extratropical rain-on-snow events, snowmelt, local convective precipitation, tropical storms, and release of ice jams. The reported knowledge of weather systems that induce flooding suggested that professionals did not have a strong grasp on climate-flood linkages, particularly among those engaged in policy development (Fig. 5). Many write-in answers indicated that individuals often did not consider the atmosphere-land surface complexity beyond that of a simple input-output system.

Individuals were asked about their beliefs on future flooding risk and two questions pertaining to perceptions of community knowledge and preferences around climate adaptation planning. First, responses indicated that approximately one-third of all professionals surveyed were unsure about community perceptions of climate science and the importance of implementing climate adaptation practices into flood hazard mitigation. Practitioners agreed that communities had some understanding of climate science that was either basic or good. Practitioners disagreed on the community desire to incorporate climate adaptation practices into flood mitigation planning, which may reflect the politically contentious nature of climate change in US political discourse and policymaking more generally. Previous research has demonstrated disconnections between public climate-flood risk perceptions and expert opinion (e.g., Hamilton et al., 2016; Ogunbode et al., 2017; Shepard et al., 2018). In this case study, professionals disagreed on both community perceptions (Table 4) and climate education (Table 5). While there may be conceptual differences in the beliefs of lay people and experts, we possibly take for granted that experts effectively understand and represent complex community needs and beliefs in the flood mitigation planning process.

\subsection{Perceptions of flooding expertise and social networks of professionals}

As previously described, $52 \%$ of flooding professionals within Tompkins County reported that they had a good understanding of flood risk mitigation, and $40 \%$ reported that they did not, but had a resource who could inform them, suggesting a well-connected network among professionals. Survey results indicate strong disagreement among flooding professionals as to which socioeconomic losses constitute a flood (Table 2), incomplete knowledge of the spatial extent of flooding within Tompkins County (Fig. 1), disagreement on anticipated community needs (Fig. 3b), weak understanding of climate-weather-flood linkages (Fig. 5), and some disagreement on community perceptions on climate adaptation (Tables 4 and 5).

The results of this research suggest a case in which practitioners may believe that they are well informed and share commonly held beliefs, while in reality the network of flooding professionals is less well established or holds divergent perceptions or terminologies regarding flooding. Instances in which decision makers believe their perspective is commonly held can open problematic possibilities and new vulnerabilities. Flood risk is a particularly difficult problem to address, owing to the infrequent nature of hydrologic extremes, nonlinear relationship between rainfall, runoff, and exposure, and potential socioeconomic feedbacks that develop between society and flood hazards (e.g., the "levee effect"; Collenteur et al., 2015). The large number of professionals who reported that they have a strong grasp of the subject could potentially indicate a susceptibility to cognitive biases influencing flood mitigation planning and design (Merz et al., 2015). For example, practitioners may be particularly susceptible to overconfidence and confirmation bias with respect to their currently held understanding of existing flood risks.

In developing the current estimate of flood frequency from aggregated reports of historical events, we reached a relatively accurate appraisal of flooding hazard (Figs. 1 and 4). This result demonstrates that flood mitigation can benefit strongly if the knowledge of independent institutions is properly leveraged (e.g., Serra-Llobet et al., 2016). In other cases, 
this research identifies gaps in the social networks of flooding professionals. Inflexibility among professionals to consider variations in project goals or risk tolerance can lead to undesirable flood mitigation outcomes (Downton et al., 2005). Disagreements on the definitions of flooding and community preferences for flood mitigation are perhaps expected results at the inception of a flood mitigation project and present opportunities for flooding professionals to engage more directly across disciplines.

Implementation of emerging robust decision-making frameworks (e.g., Prudhomme 2010; Brown et al., 2012) commonly dictate that a bottom-up approach be taken with regard to defining the problem and weighting desirable outcomes. These approaches place significant emphasis on understanding community vulnerability (Pielke et al., 2012) as the initial objective. Our results suggest that professionals engaging in flood mitigation within Tompkins County are in agreement about exposure (Fig. 3a), but have some disagreement around flood vulnerabilities (Fig. 1) and anticipated needs (Fig. 3b). Substantial differences emerged in how the six groups of professionals responded to certain questions. ESR preferred to define flooding from a classic perspective, focusing on hydrologically relevant metrics (e.g., the $n$-year discharge and exceedance of bankfull discharge), whereas individuals in planning, government, and advocacy defined flooding very broadly, from a bottom-up perspective of the associated socioeconomic losses. This particular result is not surprising as there is substantial variation in professional norms among the participating flood mitigation roles owing to education, experience, and their respective audiences/constituencies.

Distinct institutions working on flood mitigation may engage differently with primary and secondary data sources. For example, engineering, science, and biophysical research groups are typically focused on the collection and interpretation of meteorological and hydrologic data, while those engaged in public outreach may be more responsible for the collection and interpretation of socio-hydrologic data (i.e., historical flooding economic losses, migration), and governmental organizations may best understand policy implications of flood investments. The organization of social networks of professionals working in the realm of flood risk reduction remains a fairly unstudied subject, though it is particularly relevant as communication of highly uncertain information among professional disciplines remains a challenging task (e.g., Pappenberger et al., 2013; Morss et al., 2005; Downton et al., 2005). Social organizations may lead to the development of risk perception networks, whereby clusters of individuals share the same risk perception (Scherer and Cho, 2003). Conversely, dissimilar groups may tend to develop less connected relationships, where information quality is only high within a subset of organizations and shared only when necessary. Finally, disagreement surrounding the role of primary data and expression of hydrologic uncertainty can lead to suboptimal solutions or inaction (e.g., Downton et al., 2005).

Independently operating institutions at the local level commonly hold individual goals (Butler and Pidgeon, 2011; Measham et al., 2011), which may be distinct from the collective flood risk mitigation goal. Given their orientation and obligations toward voters and taxpayers, governing organizations are commonly driven by a desire for continued local economic (re)development (Molotch, 1999) as well as preoccupied with concerns around "blame" and "credit" for social outcomes (Leong and Howlett, 2017). This sometimes results in a narrow temporal focus and decisions that are made with limited consideration for decadal or longer processes (Gober and Wheater, 2015). Private firms may be concerned with maintaining profitable contracts, job security, ethics, and liability. NGOs and advocacy groups may be concerned with developing and maintaining public interest (Lorenzoni and Pidgeon, 2006). Research organizations are often concerned with developing new science and engineering techniques, with a tendency to avoid advocacy and maintenance of impartial stances on controversial subjects (Singh et al., 2014).

Disconnections among the network of professionals could also be related to compartmentalization of urban and nonurban problems. Tompkins County contains 1 urban center (City of Ithaca) and 14 less densely populated towns and villages. Observed differences in flooding perception among professionals could stem from the differences in community structures and land use within Tompkins County. Urban fill substantially alters the hydrologic response of urban areas, potentially confounding the relationship between rainfall and runoff (Knighton et al., 2014) that is not experienced in less developed areas with native soils. We note that reports of flooding and flood loss claims are greatest within the City of Ithaca (TC, 2013), possibly suggesting that a combination of regional hydrology and population density is driving the perception of flooding risk and the need for mitigation within the City of Ithaca; however, Marjerison et al. (2016), through a broader spatial study, suggest that local population density may not be a sufficient regional factor to determine flooding frequency perception. Beyond density, urban vulnerabilities and problems are often considered to be distinct from nonurban areas due to greater sociopolitical institutional complexity and less deliberate community planning (Zevenbergen et al., 2008).

Strong networks of professionals have been demonstrated to simplify decision-making, even in challenging situations (e.g., Bracken et al., 2016). Efforts to refine the flood hazard and risk profile of Tompkins County that make the effort to involve members of all disciplines explicit may build trust and communication among practitioners (Morss et al., 2005) and the public. Work that strives to leverage the knowledge of independently operating institutions and the public to define the problem statement and guide mitigation practices ultimately improves outcomes (e.g., Serra-Llobet et al., 
2016; Edelenbos et al., 2017). Public willingness to take risk reduction measures has previously been attributed myriad variables including actual risk and societal norms (Lo, 2013), income (Lo, 2014), exposure to or protection from past events (Di Baldassarre et al., 2013), and trust in expert opinion (Wachinger et al., 2013). Though disagreement between flooding practitioners and the public may occur, establishing these social connections could be an important step towards establishing trust, building public support for mitigation projects, and opening opportunities to collect sociohydrologic data which could improve flood mitigation planning and design.

\subsection{Broader impacts}

European nations (e.g., Næss et al., 2005), the UK (e.g., Brown and Damery, 2002), African and Asian nations (e.g., Huntjens et al., 2011), and the USA face the prospect of enacting water governance and developing policy within a changing climate. Recent research has focused heavily on the shortcomings of top-down approaches to flood hazard mitigation as enacted by a variety of governmental organizations. For example, Brown and Damery (2002) explore the structural issues present in a top-down governance scheme within the UK and conclude that a focus on hazard leads to improper problem definitions and "undersocialized" solutions. Subsequent research has proposed that governance leveraging both top-down and bottom-up schemes could improve the efficiency with which a nation incorporates societal vulnerability information into policy (e.g., Pahl-Wostl et al., 2010), thereby lowering societal risk.

Recent applications of decision analysis frameworks for flood mitigation within Europe (e.g., Evers et al., 2018) and the USA (e.g., J. Knighton et al., 2017) highlight the technical potential of these approaches, yet as a research community, we have not fully explored these frameworks outside of a handful of carefully controlled case studies. As more attention is being given to bottom-up approaches as a potential panacea for flood hazard mitigation, a critical assessment of governmental organizations, institutions, and practitioners becomes more necessary to explore possibilities for new unforeseen vulnerabilities that may emerge.

It is worth discussing that several aspects of our study catchment may have implications for how these results can be interpreted and applied to other locations. Our research focuses exclusively on a network of professionals within Tompkins County, New York (USA), with a distinctly bottom-up structure for flood governance. The county is moderately sized (population of 100000 ) and experiences moderate flooding $(\sim 9$-year recurrence interval for socioeconomic riverine flood losses).

With respect to county population and flood loss frequency, we can possibly anticipate that the social connectedness of professionals would increase with increasing community size and flood frequency. Both larger populations and increased frequency of hazards could lead to more complete records of historical floods and increased connectivity among professionals. It is possible that increased exposure to flood frequency would reduce cognitive biases (e.g., Merz et al., 2015), leading to an "adaptation effect" (Di Baldassarre et al., 2015). Conversely, less exposure, as would be expected with a smaller population and less flooding risks, would be expected to decrease social understanding of flooding risks (Collenteur et al., 2015) and less established networks of professionals.

Broadly, there are several aspects of this research which may allow our results to be more globally applicable. First, the local governmental and institutional organization of this case study mirrors that of other US and European cities, which suggests the possibility of similar institutional vulnerabilities associated with local governmental, private, and community organizations. For example, Bracken et al. (2016), studying flood management within the UK, describe a similarly loose coalition of experts from governmental and nongovernmental organizations to those observed within our research. Second, the reliance of bottom-up decision analysis frameworks on networks of people exists independent of local governmental structure, and would likely contribute similar vulnerabilities as we have observed. Merz et al. (2015) review a series of historical floods across Europe that resulted in increased devastation as a result of surprise. Surprise is then attributed by Merz et al. (2015) to cognitive biases "hardwired in the human brain." It is possible that the divergent perceptions and definitions that we observe among Tompkins County professionals are indicative of universal human traits, rather than simply a local phenomenon. Finally, our methodology is easily adapted, and could be applied to uncover new vulnerabilities in parallel governmental structures in other nations.

\section{Conclusion}

Complex decisions involving highly uncertain inputs can potentially be reduced to more manageable problems, given the recent improvements to, and wider application of, bottom-up vulnerability-based decision analysis frameworks. This family of methodologies relies heavily on the precise definition of system vulnerabilities so that uncertain inputs (e.g., climate projections of extreme rainfall) can be readily mapped to a stakeholder-relevant metric of concern. In flood risk analysis these frameworks are proving particularly useful as they may help to avoid debates around the reliability of future climate projections by placing this information in the context of sensitivity to stakeholder-relevant outcomes. In cases in which risk sensitivity to climate variability is low, discussions on the reliability of climate projections can be readily avoided. Further, there is an emerging consensus that flood risk analysis should directly consider the unique characteristics of the atmospheric mechanisms that induce flooding. 
Research advances have demonstrated that explicitly separating storms by weather types allows for stronger inferences on future flooding hazards.

Flood hazard and risk mitigation in the USA is often carried out at the local level by an informal collection of governmental, nongovernmental, private, and academic institutions. Previous research has observed variations in how institutions approach flood hazard, owing to differences in educational and professional backgrounds, variations in their relationship to socio-hydrologic data, and which goals or outcomes are deemed desirable. Given these discrepancies, there is a strong need to review differences among disciplines to ensure that emerging bottom-up vulnerability-based frameworks can be readily incorporated into local planning efforts.

Our research demonstrates that there are broad differences in belief among practicing professionals within Tompkins County, New York, USA, as to what socioeconomic losses constitute a flooding event and spatially disaggregated knowledge of historically flooded locations. There was strong agreement on the frequency of flooding experienced by residents, but disagreement around the desired level of protection from a flood mitigation effort. These results suggest that there is some variance among flooding professionals in the definition of community vulnerability to flooding. Undisclosed or unknown disparities in perceptions among flooding practitioners could serve as barriers to successfully implementing vulnerability-based frameworks for decision analysis. Developing strong definitions of flooding vulnerability may not require explicit agreement among all practitioners, but rather venues that allow for productive processes of deliberation. These venues necessarily involve multiple, diverse stakeholders, whose input shapes an outcome that all parties can agree is procedurally fair and acceptable.

Explicit consideration of climate-flood linkages showed similar barriers based on practitioners' knowledge. Professionals identified historical events induced by five unique mechanisms, but failed to identify these types of weather events as important causes of local floods. Among the survey results there is an intuitive sense that intense rain causes flooding, though it is possible this limited understanding prevents conceptual connections of local events to regional and global climate patterns. These discrepancies could serve as a barrier to implementing important advances in flood risk engineering that aim to use relevant climate projections to inform local planning.

In aggregate, the knowledge base of the Tompkins County flood practitioners served to provide a well-defined picture of community vulnerability and perceptions, though the beliefs of individuals varied. Previous research suggests that collaborative efforts can work to improve connections between social networks of experts and lay people. This research demonstrates the need for interdisciplinary research, planning, and design throughout flood risk mitigation and climate adaptation planning to maintain strong social con- nections, not just between lay people and experts, but among experts.

Data availability. Our data are publically available in Knighton (2018).

Supplement. The supplement related to this article is available online at: https://doi.org/10.5194/hess-22-5657-2018-supplement.

Author contributions. Research concept design was the joint effort of JK, OT, and MTW. Survey design, distribution, and collection of responses were performed by JK and OT. Data analysis was performed by JK. Interpretation of the results and discussion was performed by JK, RE, and MTW.

Competing interests. The authors declare that they have no conflict of interest.

Acknowledgements. This research was supported by an Engaged Opportunity Grant from the Cornell University Office of Engagement Initiatives. We acknowledge the contributions of the Tompkins County Environmental Management Council in identifying flood hazard mitigation practitioners within Tompkins County. We specifically thank Michael Thorne (City of Ithaca Superintendent of Public Works) and Scott Doyle (Tompkins County Planning Department) for their guidance on this research.

Edited by: Xing Yuan

Reviewed by: two anonymous referees

\section{References}

Agel, L., Barlow, M., Qian, J. H., Colby, F., Douglas, E., and Eichler, T.: Climatology of daily precipitation and extreme precipitation events in the northeast United States, J. Hydrometeorol., 16, 2537-2557. https://doi.org/10.1175/JHM-D-14-0147.1, 2015.

Birkholz, S., Muro, M., Jeffrey, P., and Smith, H. M.: Rethinking the relationship between flood risk perception and flood management, Sci. Total Environ., 478, 12-20, https://doi.org/10.1016/j.scitotenv.2014.01.061, 2014.

Blair, P. and Buytaert, W.: Socio-hydrological modelling: a review asking “why, what and how?", Hydrol. Earth Syst. Sci., 20, $443-$ 478, https://doi.org/10.5194/hess-20-443-2016, 2016.

Bracken, L. J., Oughton, E. A., Donaldson, A., Cook, B., Forrester, J., Spray, C., Cinderby, S., Passmore, D., and Bissett, N.: Flood risk management, an approach to managing cross-border hazards, Nat. Hazards, 82, 217-240, https://doi.org/10.1007/s11069016-2284-2, 2016.

Brown, C., Ghile, Y., Laverty, M., and Li, K.: Decision scaling: Linking bottom-up vulnerability analysis with climate projections in the water sector, Water Resour. Res., 48, 2012. 
Brown, J. D. and Damery, S. L.: Managing flood risk in the UK: towards an integration of social and technical perspectives, T. I. Brit. Geogr., 27, 412-426, 2002.

Burby, R. J.: Flood insurance and floodplain management: the US experience, Global Environ. Chang., 3, 111-122, https://doi.org/10.1016/S1464-2867(02)00003-7, 2001.

Butler, C. and Pidgeon, N.: From "flood defence" to "flood risk management": exploring governance, responsibility, and blame, Environ. Plann. C, 29, 533-547, https://doi.org/10.1068/c09181j, 2011.

Clarvis, M. H. and Engle, N. L.: Adaptive capacity of water governance arrangements: a comparative study of barriers and opportunities in Swiss and US states, Reg. Environ. Change, 15, 517-527, https://doi.org/10.1007/s10113-013-0547-y, 2015.

Collenteur, R. A., de Moel, H., Jongman, B., and Di Baldassarre, G.: The failed-levee effect: Do societies learn from flood disasters?, Nat. Hazards, 76, 373-388, https://doi.org/10.1007/s11069-0141496-6, 2015.

de Brito, M. M. and Evers, M.: Multi-criteria decision-making for flood risk management: a survey of the current state of the art, Nat. Hazards Earth Syst. Sci., 16, 1019-1033, https://doi.org/10.5194/nhess-16-1019-2016, 2016.

DeGaetano, A. T.: Time-dependent changes in extremeprecipitation return-period amounts in the continental United States, J. Appl. Meteorol. Clim., 48, 2086-2099, https://doi.org/10.1175/2009JAMC2179.1, 2009.

Di Baldassarre, G., Viglione, A., Carr, G., Kuil, L., Salinas, J. L., and Blöschl, G.: Socio-hydrology: conceptualising humanflood interactions, Hydrol. Earth Syst. Sci., 17, 3295-3303, https://doi.org/10.5194/hess-17-3295-2013, 2013.

Di Baldassarre, G., Viglione, A., Carr, G., Kuil, L., Yan, K., Brandimarte, L., and Blöschl, G.: Debates-Perspectives on socio-hydrology: Capturing feedbacks between physical and social processes, Water Resour. Res., 51, 4770-4781, https://doi.org/10.1002/2014WR016416, 2015.

Di Baldassarre, G., Brandimarte, L., and Beven, K.: The seventh facet of uncertainty: wrong assumptions, unknowns and surprises in the dynamics of human-water systems, Hydrolog. Sci. J., 61, 1748-1758, https://doi.org/10.1080/02626667.2015.1091460, 2016.

Downton, M. W., Morss, R. E., Wilhelmi, O. V., Gruntfest, E., and Higgins, M. L.: Interactions between scientific uncertainty and flood management decisions: Two case studies in Colorado, Global Environ. Chang., 6, 134-146, https://doi.org/10.1016/j.hazards.2006.05.003, 2005.

Easton, Z. M., Gérard-Marchant, P., Walter, M. T., Petrovic, A. M., and Steenhuis, T. S.: Hydrologic assessment of an urban variable source watershed in the northeast United States, Water Resour. Res., 43, W03413, https://doi.org/10.1029/2006WR005076, 2007.

Edelenbos, J., Van Buuren, A., Roth, D., and Winnubst, M.: Stakeholder initiatives in flood risk management: exploring the role and impact of bottom-up initiatives in three "Room for the River" projects in the Netherlands, J. Environ. Plann. Man., 60, 47-66, https://doi.org/10.1080/09640568.2016.1140025, 2017.

Elliott, R. and Rush, E: Stormy Waters: The Fight Over New York City's Flood Lines, Harper's Monthly, 2017.

Evers, M., Almoradie, A., and de Brito, M. M.: Enhancing Flood Resilience Through Collaborative Modelling and Multi-criteria
Decision Analysis (MCDA), Urban Disaster Resilience and Security, 221-236, https://doi.org/10.1007/978-3-319-68606-6_14, 2018.

Federal Emergency Management Agency (FEMA): Flood Risk and Insurance: Know the Facts, available at: https://www.fema.gov/media-library-data/ 1435760601581-d4712885b8b40afcaab671d02333ff2a/FS_

FloodRisk_nInsuranceKnowtheFacts_May2015.pdf (last access: 23 October 2018), 2015.

Federal Emergency Management Agency (FEMA): National Flood Hazard Layer, available at: https://www.fema.gov/ national-flood-hazard-layer-nfhl (last access: 23 October 2018), 2018.

Few, R.: Flooding, vulnerability and coping strategies: local responses to a global threat, Prog. Dev. Stud., 3, 43-58, https://doi.org/10.1191/1464993403ps049ra, 2003.

Fry, J., Xian, G., Jin, S., Dewitz, J., Homer, C., Yang, L., Barnes, C., Herold, N., and Wickham, J.: Completion of the 2006 national land cover database for the conterminous United States, Photogramm. Eng. Rem. S., 77, 858-864, 2011.

Gober, P. and Wheater, H. S.: Debates - Perspectives on socio-hydrology: Modeling flood risk as a public policy problem, Water Resour. Res., 51, 4782-4788, https://doi.org/10.1002/2015WR016945, 2015.

Haer, T., Botzen, W. W., and Aerts, J. C.: The effectiveness of flood risk communication strategies and the influence of social networks - Insights from an agentbased model, Environmental Science and Policy, 60, 44-52, https://doi.org/10.1016/j.envsci.2016.03.006, 2016.

Hamilton, L. C., Wake, C. P., Hartter, J., Safford, T. G., and Puchlopek, A. J.: Flood realities, perceptions and the depth of divisions on climate, Sociology, 50, 913-933, https://doi.org/10.1177/0038038516648547, 2016.

Harries, T.: Feeling secure or being secure? Why it can seem better not to protect yourself against a natural hazard, Health Risk Soc., 10, 479-490, https://doi.org/10.1080/13698570802381162, 2008.

Harries, T. and Penning-Rowsell, E.: Victim pressure, institutional inertia and climate change adaptation: The case of flood risk, Global Environ. Chang., 21, 188-197, https://doi.org/10.1016/j.gloenvcha.2010.09.002, 2011.

Hermanowicz, J. C.: The great interview: 25 strategies for studying people in bed, Qual. Sociol., 25, 479-499, 2002.

Hirabayashi, Y, Mahendran, R., Koirala, S., Konoshima, L., Yamazaki, D., Watanabe, S., Kim, H., and Kanae, S.: Global flood risk under climate change, Nat. Clim. Change, 3, 816-821, https://doi.org/10.1038/nclimate1911, 2013.

Huntjens, P., Pahl-Wostl, C., Rihoux, B., Schlüter, M., Flachner, Z., Neto, S., Koskova, R., Dickens, C., and Nabide Kiti, I.: Adaptive water management and policy learning in a changing climate: a formal comparative analysis of eight water management regimes in Europe, Africa and Asia, Environ. Policy Gov., 21, 145-163, 2011.

Ithaca Times: UPDATE: Flooding reported in Ithaca, available at: http://www.ithaca.com/ news/update-flooding-reported-in-ithaca/article

8582a8fc-f712-11e7-bf66-0fdcdebf79f7.html, last access: 23 October 2018. 
Ivancic, T. J. and Shaw, S. B.: Examining why trends in very heavy precipitation should not be mistaken for trends in very high river discharge, Climatic Change, 133, 681-693, https://doi.org/10.1007/s10584-015-1476-1, 2015.

Johnson, H.: The New York State Flood of July 1935. Water-Supply Paper 773-E, United States Government Printing Office, Washington, D.C., 1936

Kasprzyk, J. R., Nataraj, S., Reed, P. M., and Lempert, R. J.: Many objective robust decision making for complex environmental systems undergoing change, Environ. Modell. Softw., 42, 55-71, https://doi.org/10.1016/j.envsoft.2012.12.007, 2013.

Knighton, J.: Tompkins County Flood Expert Survey, HydroShare, https://doi.org/10.4211/hs.93dbbcda406349e691030e92c882fb3a, 2018.

Knighton, J., White, E., Lennon, E., and Rajan, R.: Development of probability distributions for urban hydrologic model parameters and a Monte Carlo analysis of model sensitivity, Hydrol. Process., 28, 5131-5139, https://doi.org/10.1002/hyp.10009, 2014.

Knighton, J., Steinschneider, S., and Walter, M. T.: A VulnerabilityBased, Bottom-up Assessment of Future Riverine Flood Risk Using a Modified Peaks-Over-Threshold Approach and a Physically Based Hydrologic Model, Water Resour. Res., 53, 10043-10064, https://doi.org/10.1002/2017WR021036, 2017.

Knighton, J. O. and Walter, M. T.: Critical rainfall statistics for predicting watershed flood responses: rethinking the design storm concept, Hydrol. Process., 30, 3788-3803, https://doi.org/10.1002/hyp.10888, 2016.

Knighton, J. O., DeGaetano, A., and Walter, M. T.: Hydrologic State Influence on Riverine Flood Discharge for a Small Temperate Watershed (Fall Creek, United States): Negative Feedbacks on the Effects of Climate Change, J. Hydrometeorol., 18, 431-449, https://doi.org/10.1175/JHM-D-16-0164.1, 2017.

Lane, S. N., Landström, C., and Whatmore, S. J.: Imagining flood futures: risk assessment and management in practice, Philos. T. R. Soc. A, 369, 1784-1806, 2011.

Leong, C. and Howlett, M.: On credit and blame: disentangling the motivations of public policy decision-making behaviour, Policy Sci., 50, 599-618, https://doi.org/10.1007/s11077-017-92904, 2017.

Lo, A. Y.: The role of social norms in climate adaptation: Mediating risk perception and flood insurance purchase, Global Environ. Chang., 23, 1249-1257, https://doi.org/10.1016/j.gloenvcha.2013.07.019, 2013.

Lo, A. Y.: Negative income effect on perception of longterm environmental risk, Ecol. Econ., 107, 51-58, https://doi.org/10.1016/j.ecolecon.2014.08.009, 2014.

Lorenzoni, I. and Pidgeon, N. F.: Public views on climate change: European and USA perspectives, Climatic Change, 77, 73-95, https://doi.org/10.1007/s10584-006-9072-z, 2006.

Lupton, D.: Risk and emotion: towards an alternative theoretical perspective, Health Risk Soc., 15, 634-647, https://doi.org/10.1080/13698575.2013.848847, 2013.

Lyles, W., Berke, P., and Smith, G.: A comparison of local hazard mitigation plan quality in six states, USA, Landscape Urban Plan., 122, 89-99, https://doi.org/10.1016/j.landurbplan.2013.11.010, 2014.

Marjerison, R. D., Walter, M. T., Sullivan, P. J., and Colucci, S. J.: Does Population Affect the Location of Flash Flood
Reports?, J. Appl. Meteorol. Climatol., 55, 1953-1963, https://doi.org/10.1175/JAMC-D-15-0329.1, 2016.

Masuda, J. R. and Garvin, T.: Place, culture, and the social amplification of risk, Risk Anal., 26, 437-454, https://doi.org/10.1111/j.1539-6924.2006.00749.x, 2006.

Mathias, S. A., McIntyre, N., and Oughton, R. H.: A study of non-linearity in rainfall-runoff response using $120 \mathrm{UK}$ catchments, J. Hydrol., 540, 423-436, https://doi.org/10.1016/j.jhydrol.2016.06.039, 2016.

Measham, T. G., Preston, B. L., Smith, T. F., Brooke, C., Gorddard, R., Withycombe, G., and Morrison, C.: Adapting to climate change through local municipal planning: barriers and challenges, Mitig. Adaptat. Strat. Gl., 16, 889-909, https://doi.org/10.1007/s11027-011-9301-2, 2011.

Merz, B., Aerts, J., Arnbjerg-Nielsen, K., Baldi, M., Becker, A., Bichet, A., Blöschl, G., Bouwer, L. M., Brauer, A., Cioffi, F., Delgado, J. M., Gocht, M., Guzzetti, F., Harrigan, S., Hirschboeck, K., Kilsby, C., Kron, W., Kwon, H.-H., Lall, U., Merz, R., Nissen, K., Salvatti, P., Swierczynski, T., Ulbrich, U., Viglione, A., Ward, P. J., Weiler, M., Wilhelm, B., and Nied, M.: Floods and climate: emerging perspectives for flood risk assessment and management, Nat. Hazards Earth Syst. Sci., 14, 19211942, https://doi.org/10.5194/nhess-14-1921-2014, 2014.

Merz, B., Vorogushyn, S., Lall, U., Viglione, A., and Blöschl, G.: Charting unknown waters - On the role of surprise in flood risk assessment and management, Water Resour. Res., 51, 63996416, https://doi.org/10.1002/2015WR017464, 2015.

Molotch, H.: Growth machine links: Up, down, and across, The urban growth machine: Critical perspectives two decades later, SUNY series in Urban Planning, 247-265, 1999.

Morss, R. E., Wilhelmi, O. V., Downton, M. W., and Gruntfest, E.: Flood risk, uncertainty, and scientific information for decision making: lessons from an interdisciplinary project, B. Am. Meteorol. Soc., 86, 1593-1601, https://doi.org/10.1175/BAMS-8611-1593, 2005.

Næss, L. O., Bang, G., Eriksen, S., and Vevatne, J.: Institutional adaptation to climate change: flood responses at the municipal level in Norway, Global Environ. Change, 15, 125-138, 2005.

National Climatic Data Center (NCDC): Land-Based Station Data, available at: http://www.ncdc.noaa.gov/data-access/ land-basedstation-data, last access: 23 October 2018.

Ning, L., Riddle, E. E., and Bradley, R. S.: Projected changes in climate extremes over the northeastern United States, J. Climate, 28, 3289-3310, https://doi.org/10.1175/JCLI-D-14$00150.1,2015$.

Norgaard, K. M.: Living in denial: Climate change, emotions, and everyday life, MIT Press, 2011.

Obama, B.: Establishing a federal flood risk management standard and a process for further soliciting and considering stakeholder input (United States Executive Order 13690), Washington, DC, The White House, available at: https://obamawhitehouse.archives.gov/the-pressoffice/2015/01/30/executive-order-establishing-federal-floodrisk-management-standard-and- (last access: 23 October 2018), 2015.

Ogunbode, C. A., Liu, Y., and Tausch, N.: The moderating role of political affiliation in the link between flooding experience and preparedness to reduce energy use, Climatic Change, 145, 445458, https://doi.org/10.1007/s10584-017-2089-7, 2017. 
Pahl-Wostl, C.: A conceptual framework for analysing adaptive capacity and multi-level learning processes in resource governance regimes, Global Environ. Chang., 19, 354-365, 2009.

Pahl-Wostl, C., Holtz, G., Kastens, B., and Knieper, C.: Analyzing complex water governance regimes: the management and transition framework, Environ. Sci. Policy, 13, 571-581, 2010.

Pahl-Wostl, C., Becker, G., Knieper, C., and Sendzimir, J.: How multilevel societal learning processes facilitate transformative change: a comparative case study analysis on flood management, Ecol. Soc., 18, https://doi.org/10.5751/ES-05779-180458, 2013.

Pappenberger, F., Stephens, E., Thielen, J., Salamon, P., Demeritt, D., Van Andel, S. J., Wetterhall, F., and Alfieri, L.: Visualizing probabilistic flood forecast information: expert preferences and perceptions of best practice in uncertainty communication, Hydrol. Process., 27, 132-146, https://doi.org/10.1002/hyp.9253, 2013.

Percia, S., Pavlovic, S., Laurent, M., Trypaluk, C., Unruh, D., Martin, D., and Wilhite, O.: Precipitation Frequency Atlas of the United States, 10(2.0), U.S. Department of Commerce, National Oceanic and Atmospheric Administration, 2015.

Pielke Sr., Roger, A., Wilby, R., Niyogi, D., Hossain, F., Dairuku, K., Adegoke, J., Kallos, G., Seastedt, T., and Suding, K.: Dealing with complexity and extreme events using a bottom-up, resourcebased vulnerability perspective, Extreme events and natural hazards: The complexity perspective, Geophys. Monogr., 196, 345359: https://doi.org/10.1029/2011GM001086, 2012.

Plate, E. J.: Flood risk and flood management, J. Hydrol., 267, 2-11, https://doi.org/10.1016/S0022-1694(02)00135-X, 2002.

Plummer, R., Baird, J., Bullock, R., Dzyundzyak, A., Dupont, D., Gerger Swartling, Å., Johannessen, A., Huitema, D., Lyth, A., de Lourdes Melo Zurita, M., and Munaretto, S.: Flood Governance: A multiple country comparison of stakeholder perceptions and aspirations, Environ. Policy Gov., 28, 67-81, https://doi.org/10.1002/eet.1796, 2018.

Prudhomme, C., Wilby, R. L., Crooks, S., Kay, A. L., and Reynard, N. S.: Scenario-neutral approach to climate change impact studies: application to flood risk, J. Hydrol., 390, 198-209, https://doi.org/10.1016/j.jhydrol.2010.06.043, 2010.

Rauken, T., Mydske, P. K., and Winsvold, M.: Mainstreaming climate change adaptation at the local level, Local Environment, 20, 408-423, https://doi.org/10.1080/13549839.2014.880412, 2015.

Roth, D. M. and Weather Prediction Center: Tropical cyclone rainfall in the Mid-Atlantic United States, Tropical cyclone rainfall point maxima, Silver Spring, MD, United States National Oceanic and Atmospheric Administration's National Weather Service, 2012.

Scherer, C. W. and Cho, H.: A social network contagion theory of risk perception, Risk Anal., 23, 261-267, https://doi.org/10.1111/1539-6924.00306, 2003.

Schoof, J. T. and Robeson, S. M.: Projecting changes in regional temperature and precipitation extremes in the United States, Weather and Climate Extremes, 11, 28-40, https://doi.org/10.1016/j.wace.2015.09.004, 2016.

Serra-Llobet, A., Conrad, E., and Schaefer, K.: Integrated water resource and flood risk management: comparing the US and the EU, E3S Web of Conferences, 7, https://doi.org/10.1051/e3sconf/20160720006, 2016.

Shepard, S., Boudet, H., Zanocco, C. M., Cramer, L. A., and Tilt, B.: Community climate change beliefs, awareness, and actions in the wake of the September 2013 flooding in Boulder County, Colorado, Journal of Environmental Studies and Sciences, 8, 114, https://doi.org/10.1007/s13412-018-0479-4, 2018.

Singh, G. G., Tam, J., Sisk, T. D., Klain, S. C., Mach, M. E., Martone, R. G., and Chan, K.: A more social science: barriers and incentives for scientists engaging in policy, Front. Ecol. Environ., 12, 161-166, https://doi.org/10.1890/130011, 2014.

Slater, L. J. and Villarini, G.: Recent trends in US flood risk, Geophys. Res. Lett., 43, 12428-12436, https://doi.org/10.1002/2016GL071199, 2016.

Tompkins County (TC): Tompkins County Hazard Mitigation Plan: 2013 Update, available at: http: //tompkinscountyny.gov/files2/planning/HazMitRpt/

TompkinsCountyHMPFinalDraft-July2013-ALL.pdf ～(last access: 23 October 2018), 2013.

Tompkins County (TC): Tompkins County Comprehensive Plan: Adaptation Chapter, available at: http://www.tompkinscountyny. gov/files2/planning/ComprehensivePlan/Adaptation.pdf (last access: 23 October 2018), 2015.

Tompkins County (TC): Tompkins County Contact Information for All Legislators, available at: http://www.tompkinscountyny.gov/ legislature/legislators, last access: 23 October 2018.

Trenberth, K. E.: Changes in precipitation with climate change, Clim. Res., 47, 123-138, 2011.

Troy, T. J., Pavao-Zuckerman, M., and Evans, T. P.: Debates Perspectives on socio-hydrology: Socio-hydrologic modeling: Tradeoffs, hypothesis testing, and validation, Water Resour. Res., 51, 4806-4814, https://doi.org/10.1002/2015WR017046, 2015.

United States Census: QuickFacts Tompkins County, New York, available at: https://www.census.gov/quickfacts/fact/table/ tompkinscountynewyork/PST045216 (last access: 23 October 2018), 2017.

United States Geological Survey (USGS): USGS 04233300 Fall Creek Near Ithaca NY, available at: https://waterdata.usgs.gov/ nwis/uv?04234000, last access: 23 October 2018.

Vinh Hung, H., Shaw, R., and Kobayashi, M.: Flood risk management for the RUA of Hanoi: Importance of community perception of catastrophic flood risk in disaster risk planning, Disaster Prev. Manag., 16, 245-258, https://doi.org/10.1108/09653560710739568, 2007.

Vogel, B. and Henstra, D.: Studying local climate adaptation: A heuristic research framework for comparative policy analysis, Global Environ. Chang., 31, 110-120, https://doi.org/10.1016/j.gloenvcha.2015.01.001, 2015.

Wachinger, G., Renn, O., Begg, C., and Kuhlicke, C.: The risk perception paradox-implications for governance and communication of natural hazards, Risk Anal., 33, 1049-1065, https://doi.org/10.1111/j.1539-6924.2012.01942.x, 2013.

Weinkle, J. and Pielke Jr., R.: The Truthiness about Hurricane Catastrophe Models, Sci., Technol. Hum. Val., 42, 547-576, https://doi.org/10.1177/0162243916671201, 2017.

Wheater, H. and Evans, E.: Land use, water management and future flood risk, Land Use Policy, 26, S251-S264, https://doi.org/10.1016/j.landusepol.2009.08.019, 2009.

Wing, O. E., Bates, P. D., Smith, A. M., Sampson, C. C., Johnson, K. A., Fargione, J., and Morefield, P.: Estimates of present and future flood risk in the conterminous United States, Environ. Res. Lett., 13, 034023, https://doi.org/10.1088/17489326/aaac65, 2018. 
Wobus, C., Gutmann, E., Jones, R., Rissing, M., Mizukami, N., Lorie, M., Mahoney, H., Wood, A. W., Mills, D., and Martinich, J.: Climate change impacts on flood risk and asset damages within mapped 100-year floodplains of the contiguous United States, Nat. Hazards Earth Syst. Sci., 17, 2199-2211, https://doi.org/10.5194/nhess-17-2199-2017, 2017.

Wood, M., Kovacs, D., Bostrom, A., Bridges, T., and Linkov, I.: Flood risk management: US Army Corps of Engineers and layperson perceptions, Risk Anal., 32, 1349-1368, https://doi.org/10.1111/j.1539-6924.2012.01832.x, 2012.
Zevenbergen, C., Veerbeek, W., Gersonius, B., and Van Herk, S.: Challenges in urban flood management: travelling across spatial and temporal scales, J. Flood Risk Manag., 1, 81-88, https://doi.org/10.1111/j.1753-318X.2008.00010.x, 2008. 